\title{
Magnetic resonance tomography for the early detection of occult fractures of the spinal column in patients with ankylosing spondylitis
}

\author{
Nicolas H. von der Höh ${ }^{1}$ (D) J Jeanette Henkelmann ${ }^{2}$. Jan-Sven Jarvers ${ }^{1}$. Ulrich Josef A. Spiegl ${ }^{1}$. Anna Voelker ${ }^{1}$. \\ Christoph Josten ${ }^{1} \cdot$ Christoph-Eckhard Heyde ${ }^{1}$
}

Received: 11 May 2019 / Revised: 29 October 2019 / Accepted: 18 January 2020 / Published online: 29 January 2020

(c) The Author(s) 2020

\begin{abstract}
Purpose The purpose of this study was to determine the extent to which magnetic resonance imaging (MRI) performed in patients with ankylosing spondylitis (AS) after low- and no-energy trauma leads to an improved diagnosis and, as a result, to a change in the therapeutic strategy.

Methods All patients with AS, who underwent surgery after minor traumas (low-energy traumas, LETs) and patients without trauma history (NET: no-energy trauma), were retrospectively analysed. The diagnostic and planned surgical procedure was examined initially and again after total spine MRI in patients with persistent and/or new complaints.

Results One hundred and thirty-six patients with AS after trauma were surgically treated. A total of 92 patients with LETs and 12 patients with NETs were included. After initial diagnostics (CT and X-ray) were performed in $15.4 \%$ of the patients with LET or NET $(n=16)$, we found occult fractures on MRI scans. In ten of these patients (6 LET, 4 NET) in which a previous decision was made to follow conservative therapy, no fracture indication was found on CT or X-ray. Two fracture heights were observed in six patients who experienced LET. However, on X-ray and CT, the fractures were only visible at one height. All fractures were treated surgically with stabilization and decompression if indicated.

Conclusion Considering the high percentage of our patient population with occult fractures, we recommend supplementing the basic diagnostic procedures with an MRI of the entire spinal column in patients with painful spinal column findings after minor trauma and for those with persistent pain without trauma.
\end{abstract}

\section{Graphic abstract}

These slides can be retrieved under Electronic Supplementary Material.
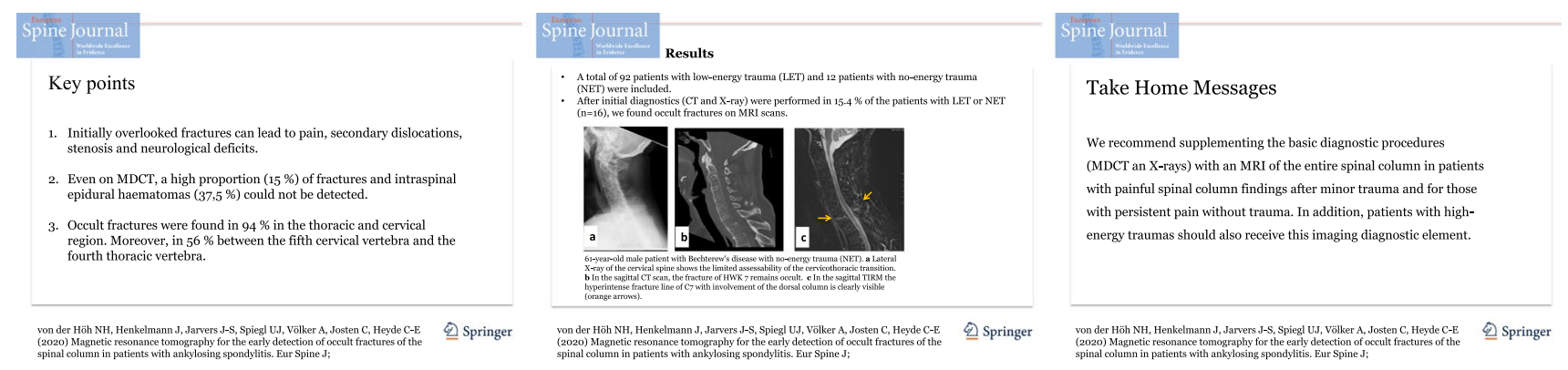

Keywords Occult fracture $\cdot$ Spinal column $\cdot$ Ankylosing spondylitis $\cdot$ MRI $\cdot$ Imaging

Electronic supplementary material The online version of this article (https://doi.org/10.1007/s00586-020-06309-7) contains supplementary material, which is available to authorized users.

Nicolas H. von der Höh

Nicolas.vonderHoeh@medizin.uni-leipzig.de

Extended author information available on the last page of the article

\section{Introduction}

Ankylosing spondylitis in its severe manifestation is associated with a high risk of vertebral body fractures due to ossification of the ligaments. In the literature, there is a four-to-ten 
time higher lifetime risk of a person with ankylosing spondylitis being affected by a fracture of the spine compared to a normal cohort [1].

However, the fragility of patients with Bechterew's disease is based on four substantial problems: long lever arm, osteoporosis, sarcopenia, and kyphosis with restriction of the visual axis $[2,10]$.

The prevalence of vertebral fractures in ankylosing spondylitis is almost 30\% with the use of WHO criteria for osteoporosis [5]. Moreover, both low bone mineral density and sarcopenia are found in the early stages of Bechterew's disease [14]. Accordingly, an adequate trauma will lead to subsequent diagnostic assessment with thin-layer computed tomography (CT) if necessary in advance of plain radiographs. In contrast, for the reasons of fragility mentioned above, there is no standard diagnostic procedure for patients who experience a low-energy trauma (LET), and diagnosis is even more challenging for patients who experience a no-energy trauma (NET). However, initially overlooked fractures can lead to pain, secondary dislocations, stenosis, and neurological deficits [16].

In Europe, there is no standard recommendation to perform an initial diagnosis using magnetic resonance imaging (MRI) of the entire spinal column. Furthermore, the current literature contains only a few cases of patients with Bechterew's disease or diffuse idiopathic skeletal hyperostosis (DISH) with occult fractures, and thus, the risk of occult fractures as a consequence remains underestimated [3, 4]. DISH is the only differential diagnosis of Bechterew's disease that is associated with ventral spondylophyte formation. In the literature, however, these two clinical diagnoses are often considered combined or partly overlapping, so data on larger patient collectives are missing.

The objective of this study was to determine to what extent standard MRI of the whole spine performed in our hospital leads to an improved diagnosis in patients with Bechterew's disease after LET or NET and thus leads to a change in the therapeutic strategy.

\section{Materials and methods}

For the purpose of the study, we evaluated the data of 136 patients with confirmed Bechterew's disease who required spinal stabilization in a level-one trauma and special spinal care centre between June 2010 and June 2018. All data were collected through a review of consecutive clinical records and imaging files. In addition to demographic data, we evaluated the accident mechanism and injury levels.

The inclusion criteria were as follows:

- Complete data set with X-ray in two planes, MDCT, and subsequent whole body magnetic resonance imaging.
- Patients who were treated without trauma history, so we called this circumstance no-energy trauma (NET).

- Patients who were treated after low-energy trauma (LET) such as falling from a standing or seated position or falling from a height below $1.5 \mathrm{~m}$, was the cause of trauma.

The exclusion criteria were as follows:

Patients who were treated for infections or metastases were excluded from the study. Furthermore, all patients with DISH were excluded. Patients with electronic devices that would prohibit MRI and those who experienced high-energy trauma, falls above $1.5 \mathrm{~m}$, high-energy traumas, bicycle falls, or severe injuries (ISS $>16$ ) were excluded.

All radiographs and MDCT scans were reviewed in detail and compared with the complementary MRI findings. In the MRI, we examined the fractures known from CT or X-rays for the trajectory of the fracture line and searched for possible intraspinal haemorrhages. In addition, we also looked for any other bone bruises, fracture lines, intraspinal haemorrhages, and other dorsal or ventral column injuries that were not apparent in MDCT or X-rays.

Whole spine MRI was performed on 1.5 T and 3.0 Tesla MRI using sagittal T1-weighted turbo spin-echo sequence, sagittal and axial and T2-weighted turbo spin-echo sequence, and sagittal inversion recovery sequences (short tau inversion recovery resp. turbo inversion recovery magnitude).

Furthermore, we analysed whether further surgical procedures were accomplished based on MRI diagnostics, which would not have been performed purely based on radiological diagnostics using thin-layer multidetector CT (MDCT).

Furthermore, we examined the documents to determine whether the occult fractures also corresponded to the clinical examination or anamnesis. Moreover, we analysed the history of other diseases, the patient's spinal fracture classification according to AO Spine, the previously planned and expanded surgical strategies, and the complications during and after surgery.

The study conforms to the Declaration of Helsinki and to local legislation. The study was reviewed and approved by our local ethics committee.

\section{Statistical analyses}

Fisher's exact test was applied for categorical data. The level of significance was $p<0.05$. We utilized the SPSS (Trademark) 20.0 statistics software program (SPSS Inc., Chicago, IL, USA) for Windows. 


\section{Results}

During the 8-year study period, 136 patients with Bechterew's disease after trauma were treated for spinal trauma. Of these, a total of 104 cases could be included in the study and fulfilled the inclusion criteria. In 92 cases, we found patients with low-energy trauma (LET). In 12 cases, we found no trauma anamnesis, so we called this circumstance no-energy trauma (NET). We excluded 32 cases. In addition, we found that fractures have occurred from falls above $1.5 \mathrm{~m}$ in eight cases, high-energy traumas in 21 cases, bicycle falls in one case, severe injuries (ISS $>16$ ) in one case and one patient has an electronic device that would prohibit MRI. The average age was $74 \pm 10$ years, and the male/female ratio was $7: 1$.
In 16 cases (15\%), occult fractures due to LET or NET were found only in MRI of the entire spinal column. However, these fractures were not visible on the previously performed imaging modalities with conventional X-ray or multidetector computed tomography (MDCT). All patients had pain in one or more regions of the spine.

Conservative therapy was initially indicated in ten patients without findings on MDCT or X-ray; four of these patients had experienced NET, and six had a LET event. The complementary total spine MRI revealed the corresponding occult fracture locations (Fig. 1). All of these with an initial conservative treatment decision had a delay in therapy until MRI and occult fracture detection over $24 \mathrm{~h}$ later. During the inpatient course, two patients (Patient No. 6 and 7) with NET developed neurological deficits (ASIA D and C) with spinal haematomas at the corresponding fracture levels.
Fig. 1 A 61-year-old male patient with Bechterew's disease. a Lateral X-ray of the cervical spine shows the limited accessability of the cervicothoracic transition. $\mathbf{b}$ In the sagittal CT scan, the fracture of HWK seven remains occult. $\mathbf{c}$ In the sagittal TIRM, the hyperintense fracture line of $\mathrm{C} 7$ with involvement of the dorsal column is clearly visible
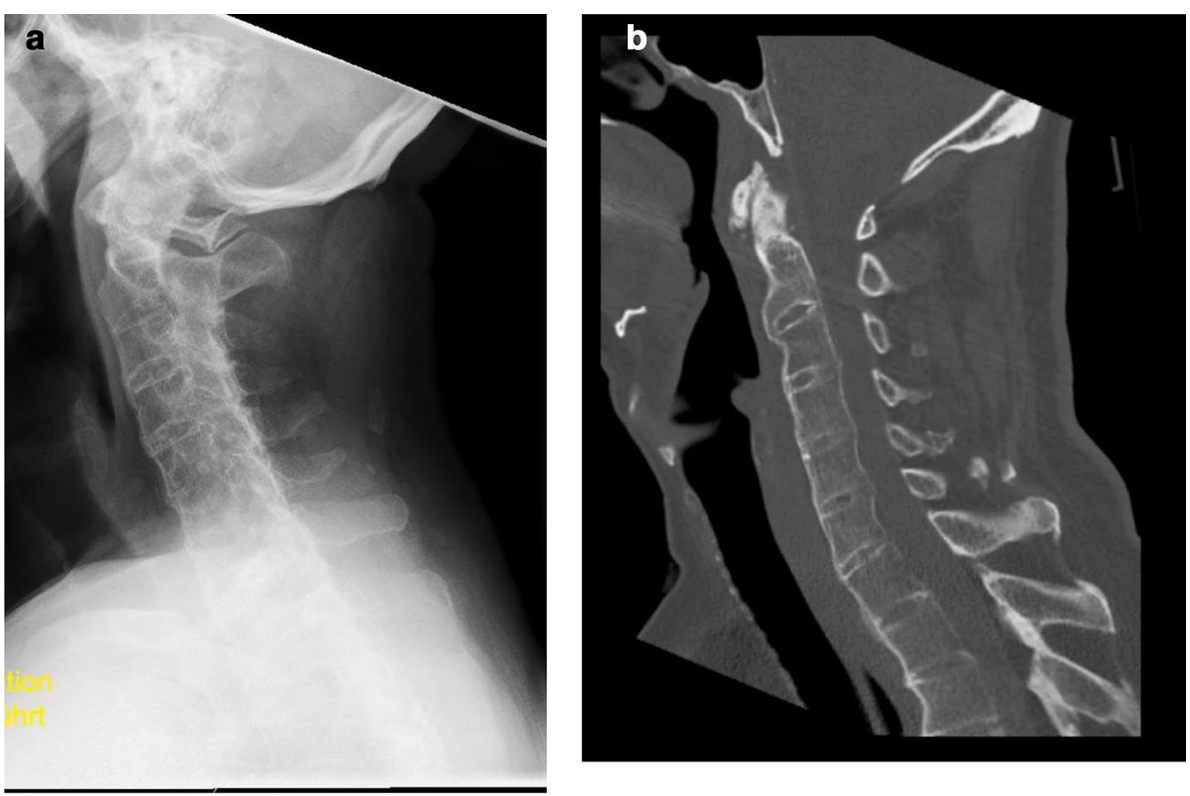

C

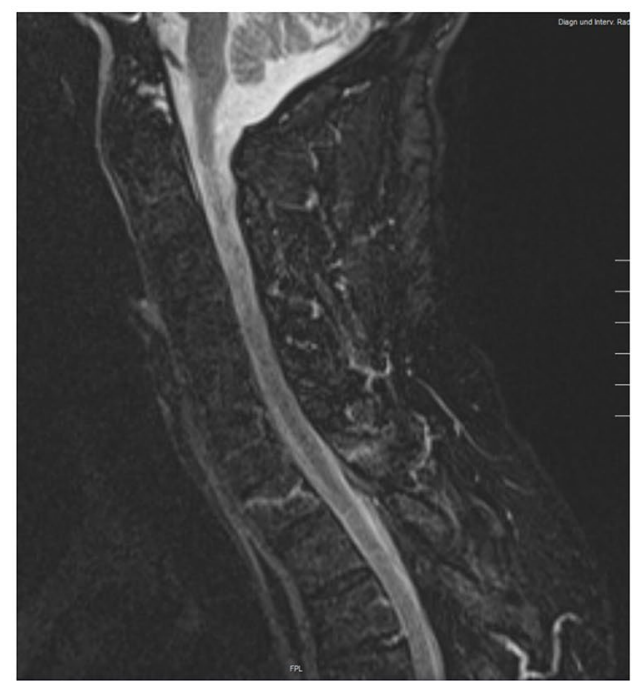


In six patients with LET, fracture localizations were found at two levels. However, on X-ray and MDCT, these fractures were only visible at one level (Table 2). In addition, MRI showed another undetected fracture in another segment or spinal section (Fig. 2). Of these six cases, four fractures were found in the cervicothoracic region. One patient with secondary occult fracture had neurological deficits upon admission (ASIA C). MDCT showed a fracture at height at T8, but intraspinal bleeding and occult fracture were found at C5/6 (Patient No. 2).

When reviewing the documentation, correlations between pain descriptions and occult fractures were found in $75 \%$ $(n=12)$ of the patients. In $94 \%(n=15)$, we located occult fractures in the thoracic and cervical region. Nine of them were located between the fifth cervical vertebra and the fourth thoracic vertebra. As additional information to the MDCT finding, epidural haematomas were found in $37.5 \%$ $(n=6)$ of patients $(p=0.0002)$; three of them had paraplegic symptoms, and the other three patients remained asymptomatic, but all epidural haematomas were decompressed. Accordingly, in patients with two fractures, the surgical procedures were extended to the second segments or heights as appropriate (see Table 3 ). In all cases, a corresponding instability was observed intraoperatively. There were no patients with three fracture localizations. All patients underwent open surgery, and the average operation time was $234 \pm 99 \mathrm{~min}$. One patient (Patient No. 12) died during surgery due to cardiovascular collapse.

The intraoperative complication rate was $25 \%$. Postoperatively, complications occurred in $56 \%$ of cases. The pulmonary system was the most frequently affected.

Information on statistical analyses is shown in Table 1. Demographics, fracture locations, AO classification, epidural bleeding, ASIA classification, other injuries, and concomitant diseases are shown in Table 2. Intraoperative

Table 1 Information on statistical analyses between MDCT and MRI using Fisher's exact test

\begin{tabular}{lccc}
\hline & MDCT & MRI & Fisher exact test \\
\hline Occult fracture $(n=16)$ & 6 & 16 & $p=0.0002$ \\
Detected & 10 & 0 & \\
Not detected & 0 & 6 & $p=0.0022$ \\
Occult secondary fracture $(n=6)$ & & \\
Detected & 0 & 0 & \\
Not detected & 6 & & \\
Epidural haematoma $(n=6)$ & 6 & \\
Detected & 0 & 0 & \\
Not detected & 6 & &
\end{tabular}

Fig. 2 a A 78-year-old ankylosing spondylitis patient with initial lateral C-spine X-ray. b Preoperative sagittal CT scan shows injury with facet fracture of Th 8-9. c Sagittal TIRM reveals a multilevel cervical and thoracic spine fracture additional fracture of C6-7 (occult in CT scan) with detection of a discrete intraspinal haematoma

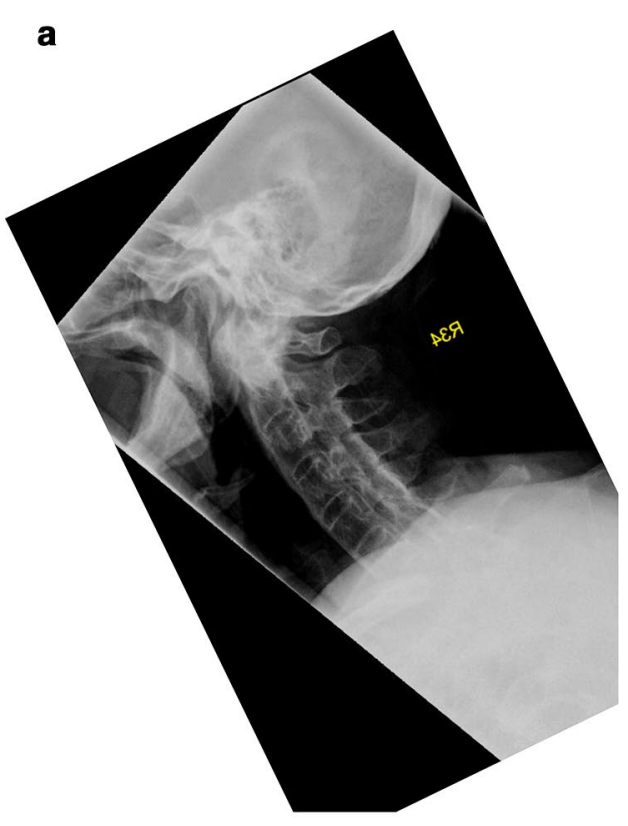

b
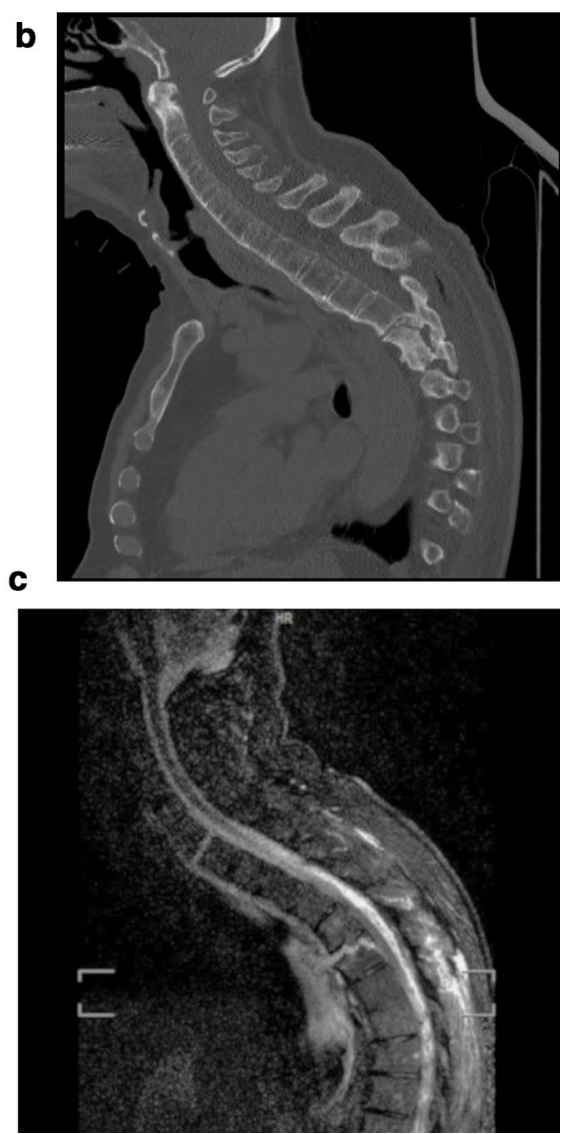


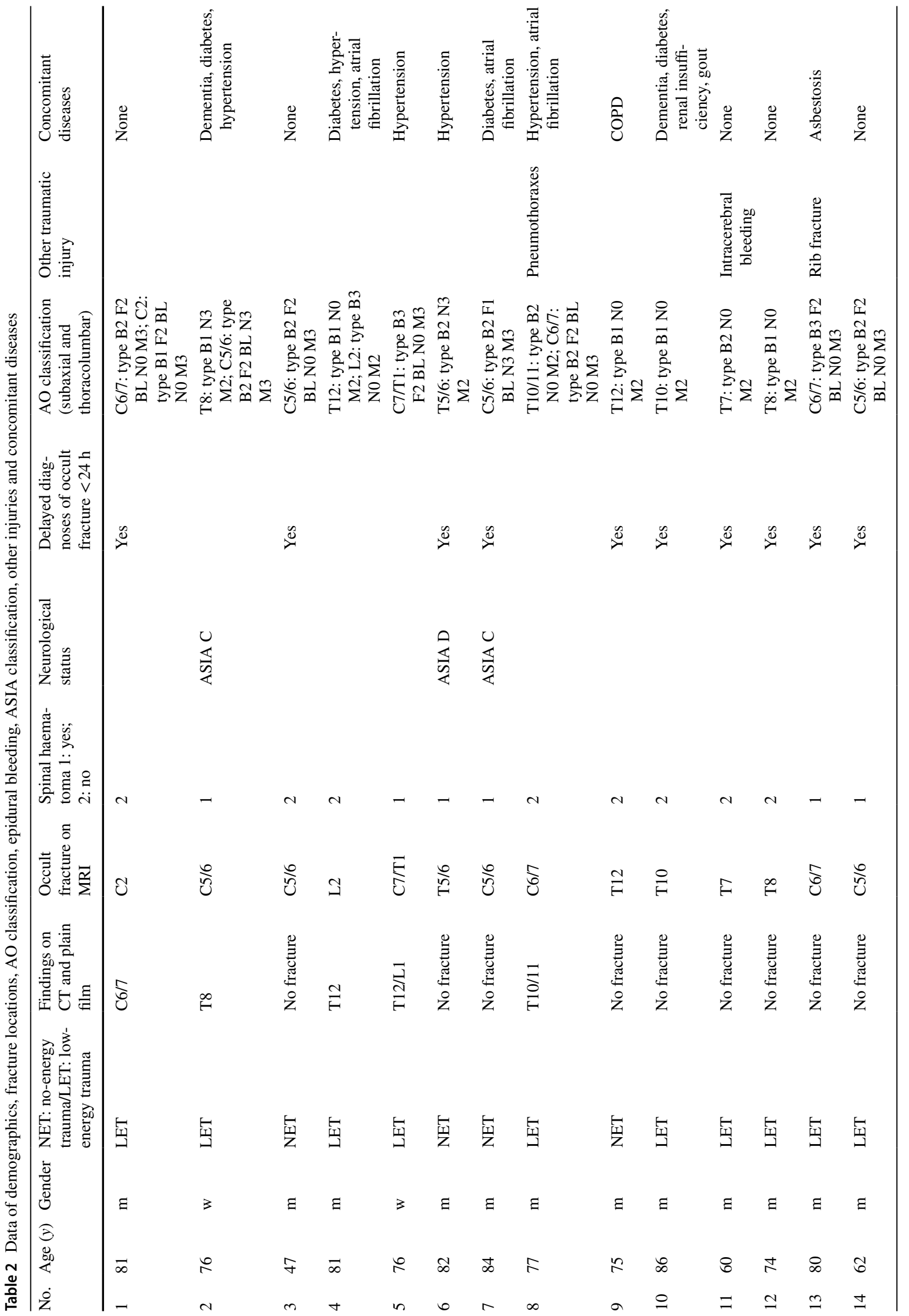




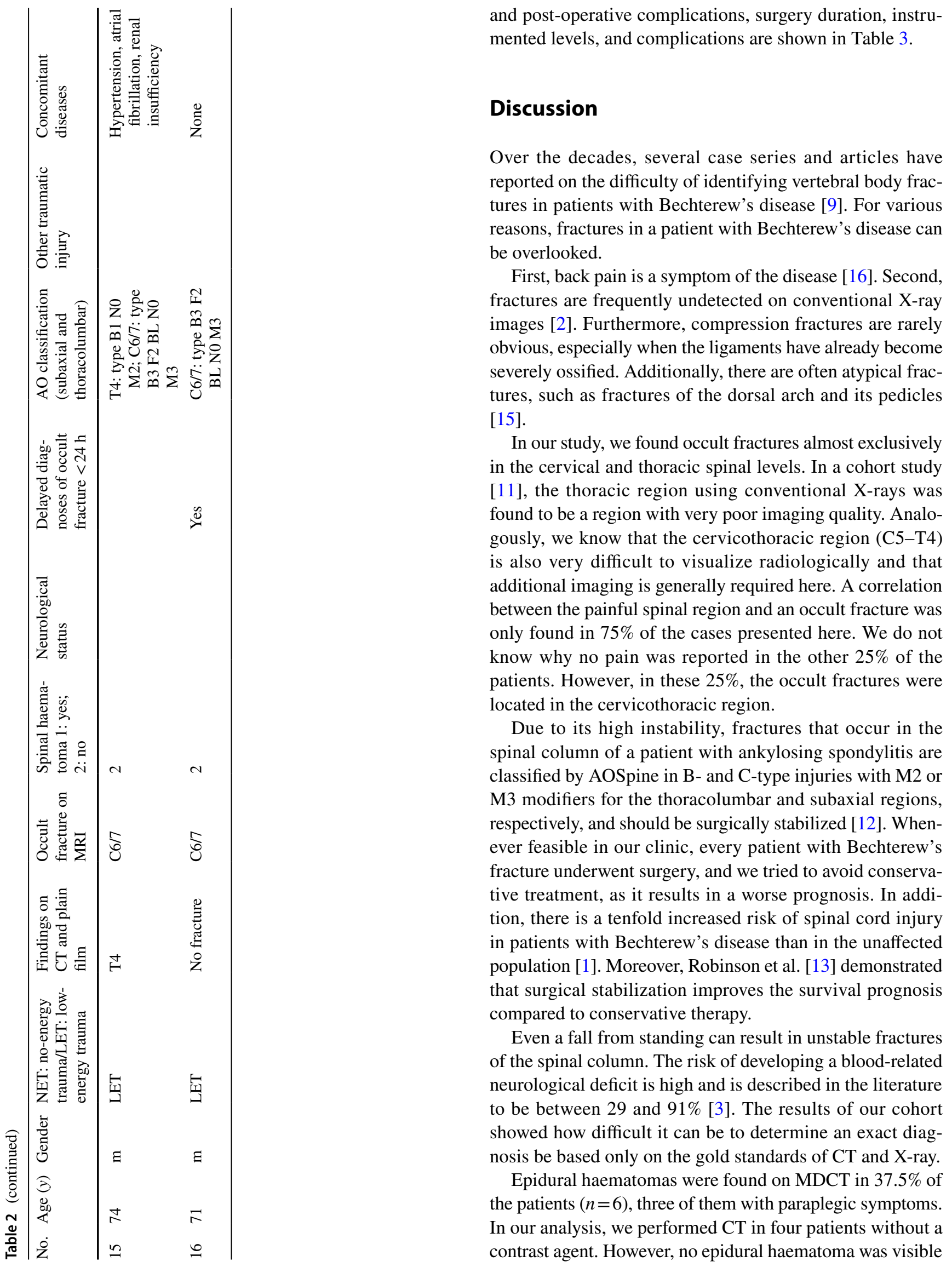


Table 3 Results of intraoperative and postoperative complications, surgery duration, instrumented levels and complications

\begin{tabular}{|c|c|c|c|c|c|}
\hline No. & $\begin{array}{l}\text { Dorsal stabilization planned on } \\
\text { the basis of MDCT and X-rays }\end{array}$ & $\begin{array}{l}\text { Extended therapy with } \\
\text { dorsal stabilization after } \\
\text { MRI }\end{array}$ & Intraoperative complications & $\begin{array}{l}\text { Surgery } \\
\text { time } \\
(\mathrm{min})\end{array}$ & Post-operative complications \\
\hline 1 & $\mathrm{C} 4-\mathrm{T} 4$ & $\mathrm{C} 0-\mathrm{T} 2$ & None & 351 & Delirium \\
\hline 2 & T6-T11 & $\mathrm{C} 3-\mathrm{T} 1$ & None & 191 & $\begin{array}{l}\text { Pneumonia, anaemia, deep wound } \\
\text { infection }\end{array}$ \\
\hline 3 & Conservative & $\mathrm{C} 3-\mathrm{T} 2$ & $\begin{array}{l}\text { Acute liver failure, compart- } \\
\text { ment syndrome }\end{array}$ & 536 & $\begin{array}{l}\text { Pneumonia, sepsis, renal insuf- } \\
\text { ficiency }\end{array}$ \\
\hline 4 & T10-L3 & T10-L5 & Nerve root avulsion & 175 & $\begin{array}{l}\text { Circulatory instability, requires } \\
\text { dialysis }\end{array}$ \\
\hline 5 & T10-L3 & C5-T3 & None & 287 & Pneumothoraxes \\
\hline 6 & Conservative & $\mathrm{T} 3-\mathrm{T} 8$ & None & 183 & None \\
\hline 7 & Conservative & $\mathrm{C} 3-\mathrm{T} 1$ & None & 148 & None \\
\hline 8 & T8-L1 & $\mathrm{C} 4-\mathrm{T} 2$ & Bleeding & 237 & Acute renal insufficiency \\
\hline 9 & Conservative & T10-L3 & None & 322 & None \\
\hline 10 & Conservative & T8-L1 & None & 188 & Respiratory insufficiency \\
\hline 11 & Conservative & $\mathrm{T} 5-\mathrm{T} 10$ & None & 187 & None \\
\hline 12 & Conservative & T5-T11 & Reanimation with death & 189 & None \\
\hline 13 & Conservative & C3-T3 & None & 155 & None \\
\hline 14 & Conservative & $\mathrm{C} 4-\mathrm{T} 2$ & None & 203 & Pneumonia \\
\hline 15 & $\mathrm{~T} 1-\mathrm{T} 7$ & C4-T7 & None & 217 & None \\
\hline 16 & Conservative & C3-T3 & None & 176 & Thrombosis \\
\hline
\end{tabular}

in the other two patients. The reason may be that the MRI scan was performed at least $24 \mathrm{~h}$ after the CT scan, and intraspinal bleeding may exhibit better contrast over that period.

There are several reasons why the significance of MRI may be limited. Notably, the long delay between the onset of symptoms and a diagnosis with less fluid intensity in the fracture region is especially noteworthy [7]. Furthermore, the use of a fat-suppressed sequence is more sensitive on magnetic resonance tomography (MRT). Wang et al. [15] demonstrated good visualization of the fracture elements and fracture lines using CT but showed limitations in the evaluation of the posterior elements in Bechterew's patients with fracture of the spinal column.

Anderson lesions, called shiny corners in conventional radiological imaging, are a process that occurs when the anterior ligament is ossified. Some of these are also interpreted as chronic fractures and can also lead to misinterpretations in diagnosing occult fractures. Additional imaging with CT and MRI is always indicated in patients with persistent pain [15].

In the opinion of the authors, the positioning of patients during CT examinations is an important factor. Fixation on a straight spine board in the kyphotic spine tends to lead to an opening of the fracture. Long-term experience has shown an improvement in acute pain in patients with Bechterew's disease by closing the fracture gap, thus restoring the original alignment. In addition, the positioning of the patient on the examination table may influence the fracture detection ability of CT imaging.

There are two case reports in the literature in which neither a single detector CT nor an MRT evaluation could provide precise fracture findings. Only MDCT permitted visualization of the occult fracture. However, indirect signs of bleeding into the spinal canal and acute intraparenchymal signal changes on MRI were observed at the painful and suspected spinal level [6]. Nevertheless, in this cohort, MDCT was performed in all cases, and unstable fractures were not detected in $15 \%$ of the overall cohort. In contrast, Khurana et al. reported that MRI imaging of the total spine provided additional fracture-related information outside of the focused zone at three segment heights above and below the known fracture site in $15 \%$ of the cases. In none of the cases did these findings lead to a change in the surgical strategy [8].

Limitations of the study are numerous. This study is retrospective and analyses a specific clinical condition. There was no comparison group. The patient age of 74 years is very high compared to that in other studies. In one of the largest reviews, the average patient age was 59.1 years [16].

However, despite the limitations of the study, the authors recommend performing a standard MRI diagnostic of the whole spine in all patients with Bechterew's disease even in the presence of a MDCT for the following reasons: 
- First, we showed that even on MDCT, a high proportion $(15 \%)$ of fractures could not be detected.

- Second, there is a high percentage of osteoporosis in this patient population for whom MRI is generally recommended.

- Third, due to the known delayed detection which may lead to a worsening of the symptoms. In our patient population this has been demonstrated by three patients with incomplete paraplegia.

- Fourth, there is a risk of intraspinal bleeding in this patient population due to the accompanying comorbidities, particularly cardiovascular diseases, which lead to the intake of blood thinners in the majority of patients.

\section{Conclusion}

The gold standard imaging modality for detecting fractures in patients with ankylosing spondylitis, in particular Bechterew's disease, is CT along with classical radiological imaging. In this study, the surgical procedure was adjusted, and the corresponding segments were stabilized when secondary occult fracture was discovered. In addition, occult fractures detected by MRI in patients without imaging information after CT and X-ray were also stabilized and if necessary, an epidural haematoma in the region was decompressed immediately.

If patients with Bechterew's disease who experience NET or LET are suffering from acute back pain, even without trauma, it is always recommended to proceed to the assumption of a fracture until it is safely excluded. In addition to the basic diagnostics with X-rays and MDCT of the painful region, we recommend prompt MRI of the entire spinal axis (possibly only a fat-suppressed sequence is needed) due to the risk of overlooking non-dislocated fractures on MDCT. Moreover, MRI indicates that intraspinal pathologies are more reliable in this study. In addition, patients with highenergy traumas now also receive this imaging diagnostic element.

Acknowledgements Open Access funding provided by Projekt DEAL.

\section{Compliance with ethical standards}

Conflict of interest None of the authors has any potential conflict of interest.

Open Access This article is licensed under a Creative Commons Attribution 4.0 International License, which permits use, sharing, adaptation, distribution and reproduction in any medium or format, as long as you give appropriate credit to the original author(s) and the source, provide a link to the Creative Commons licence, and indicate if changes were made. The images or other third party material in this article are included in the article's Creative Commons licence, unless indicated otherwise in a credit line to the material. If material is not included in the article's Creative Commons licence and your intended use is not permitted by statutory regulation or exceeds the permitted use, you will need to obtain permission directly from the copyright holder. To view a copy of this licence, visit http://creativecommons.org/licenses/by/4.0/.

\section{References}

1. Alaranta H, Luoto S, Konttinen YT (2002) Traumatic spinal cord injury as a complication to ankylosing spondylitis. An extended report. Clin Exp Rheumatol 20:66-68

2. Campagna R, Pessis E, Feydy A, Guerini H, Thévenin F, Chevrot A, Drapé J-L (2009) Fractures of the ankylosed spine: MDCT and MRI with emphasis on individual anatomic spinal structures. AJR Am J Roentgenol 192:987-995. https://doi.org/10.2214/ AJR.08.1616

3. Elgafy H, Bransford RJ, Chapman JR (2011) Epidural hematoma associated with occult fracture in ankylosing spondylitis patient: a case report and review of the literature. J Spinal Disord Tech 24:469-473. https://doi.org/10.1097/BSD.0b013e318204da02

4. Finkelstein JA, Chapman JR, Mirza S (1999) Occult vertebral fractures in ankylosing spondylitis. Spinal Cord 37:444-447

5. Ghozlani I, Ghazi M, Nouijai A, Mounach A, Rezqi A, Achemlal L, Bezza A, El Maghraoui A (2009) Prevalence and risk factors of osteoporosis and vertebral fractures in patients with ankylosing spondylitis. Bone 44:772-776. https://doi.org/10.1016/j. bone.2008.12.028

6. Harrop JS, Sharan A, Anderson G, Hillibrand AS, Albert TJ, Flanders A, Vaccaro AR (2005) Failure of standard imaging to detect a cervical fracture in a patient with ankylosing spondylitis. Spine 30:E417-E419

7. Hitchon PW, From AM, Brenton MD, Glaser JA, Torner JC (2002) Fractures of the thoracolumbar spine complicating ankylosing spondylitis. J Neurosurg 97:218-222

8. Khurana B, Karim SM, Zampini JM, Jimale H, Cho CH, Harris MB, Sodickson AD, Bono CM (2019) Is focused magnetic resonance imaging adequate for treatment decision making in acute traumatic thoracic and lumbar spine fractures seen on whole spine computed tomography? Spine J 19:403-410. https://doi. org/10.1016/j.spinee.2018.08.010

9. Leone A, Marino M, Dell'Atti C, Zecchi V, Magarelli N, Colosimo C (2016) Spinal fractures in patients with ankylosing spondylitis. Rheumatol Int 36:1335-1346. https://doi.org/10.1007/s0029 6-016-3524-1

10. Murray HC, Elliott C, Barton SE, Murray A (2000) Do patients with ankylosing spondylitis have poorer balance than normal subjects? Rheumatology 39:497-500

11. Ramiro S, Stolwijk C, van Tubergen A, van der Heijde D, Dougados M, van den Bosch F, Landewé R (2015) Evolution of radiographic damage in ankylosing spondylitis: a 12 year prospective follow-up of the OASIS study. Ann Rheum Dis 74:52-59. https ://doi.org/10.1136/annrheumdis-2013-204055

12. Reinhold M, Knop C, Kneitz C, Disch A (2018) Spine fractures in ankylosing diseases: recommendations of the spine section of the German Society for Orthopaedics and Trauma (DGOU). Glob Spine J 8:56S-68S. https://doi.org/10.1177/2192568217736268

13. Robinson Y, Willander J, Olerud C (2015) Surgical stabilization improves survival of spinal fractures related to ankylosing spondylitis. Spine 40:1697-1702. https://doi.org/10.1097/BRS.00000 00000001115

14. Sambrook P, Cooper C (2006) Osteoporosis. Lancet 367:2010 2018. https://doi.org/10.1016/S0140-6736(06)68891-0

15. Wang Y-F, Teng MM-H, Chang C-Y, Wu H-T, Wang S-T (2005) Imaging manifestations of spinal fractures in ankylosing spondylitis. AJNR Am J Neuroradiol 26:2067-2076 
16. Westerveld LA, Verlaan JJ, Oner FC (2009) Spinal fractures in patients with ankylosing spinal disorders: a systematic review of the literature on treatment, neurological status and complications. Eur Spine J 18:145-156. https://doi.org/10.1007/s0058 6-008-0764-0
Publisher's Note Springer Nature remains neutral with regard to jurisdictional claims in published maps and institutional affiliations.

\section{Affiliations}

Nicolas H. von der Höh ${ }^{1}$ (D) . Jeanette Henkelmann ${ }^{2}$. Jan-Sven Jarvers ${ }^{1}$ • Ulrich Josef A. Spiegl ${ }^{1}$. Anna Voelker ${ }^{1}$. Christoph Josten ${ }^{1}$. Christoph-Eckhard Heyde ${ }^{1}$

1 Department of Orthopaedic, Trauma and Plastic Surgery, University Hospital Leipzig, Liebigstr. 18, 04103 Leipzig, Germany
2 Department for Diagnostic and Interventional Radiology, University Hospital Leipzig, Liebigstr. 18, 04103 Leipzig, Germany 